\title{
Effect of the addition of mixture of plant components on the mechanical properties of wheat bread
}

\author{
Monika Wójcik ${ }^{1 *}$, Dariusz Dziki ${ }^{2}$, Beata Biernacka ${ }^{2}$, Renata Różyto ${ }^{1}$, Antoni Miśs ${ }^{3}$, and Waleed H. Hassoon ${ }^{2,4}$ \\ ${ }^{1}$ Department of Equipment Operation and Maintenance in the Food Industry, ${ }^{2}$ Department of Thermal Engineering, \\ University of Life Sciences, Doświadczalna 44, 20-280 Lublin, Poland \\ ${ }^{3}$ Institute of Agrophysics, Polish Academy of Sciences, Doświadczalna 4, 20-290, Lublin, Poland \\ ${ }^{4}$ Department of Food Technology, College of Food Sciences, University of Al-Qasim Green, Babylon, Iraq
}

Received November 10, 2016; accepted July 31, 2017

\begin{abstract}
A b stract. Instrumental methods of measuring the mechanical properties of bread can be used to determine changes in the properties of it during storage, as well as to determine the effect of various additives on the bread texture. The aim of this study was to investigate the effect of the mixture of plant components on the physical properties of wheat bread. In particular, the mechanical properties of the crumb and crust were studied. A sensory evaluation of the end product was also performed. The mixture of plant components included: carob fiber, milled grain red quinoa and black oat $(1: 2: 2)$ - added at $0,5,10,15,20,25 \%$ - into wheat flour. The results showed that the increase of the addition of the proposed additive significantly increased the water absorption of flour mixtures. Moreover, the use of the mixture of plant components above $5 \%$ resulted in the increase of bread volume and decrease of crumb density. Furthermore, the addition of the mixture of plant components significantly affected the mechanical properties of bread crumb. The hardness of crumb also decreased as a result of the mixture of plant components addition. The highest cohesiveness was obtained for bread with $10 \%$ of additive and the lowest for bread with $25 \%$ of mixture of plant components. Most importantly, the enrichment of wheat flour with the mixture of plant components significantly reduced the crust failure force and crust failure work. The results of sensory evaluation showed that the addition of the mixture of plant components of up to $10 \%$ had little effect on bread quality.

K e yw ords: mechanical properties, bread, quality, plant
\end{abstract} additives

\section{INTRODUCTION}

The most common bakery product in the world is bread. For consumers, key attributes of fresh bread are its external appearance, crust quality (in particular, its crispy texture), colour and aroma. As a consequence of the limi- ted shelf life of bread, such pleasant properties change. Crust staling is associated with moisture redistribution, which results in the softening of the crust, an effect not appreciated by the consumer. On the other hand, crumb staling is more complicated, as it comes about because of physicochemical changes in the bread starch (Altamirano-Fortoul et al., 2012; Besbes et al., 2014).

Qualitative assessment of bread plays an important role in parameters determined on the basis of instrumental methods for measuring the mechanical properties of bread. These methods can be employed to determine both the quality characteristics of different types of bread (Rosell and Santos, 2010; Škrbić and Filipčev, 2008) and the effect of various additives used to change the texture attributes during storage (Katina et al., 2006; Różyło et al., $2014,2015)$. The mechanical properties of bread crumb are commonly assessed via the single or double compression test texture profile analysis (TPA). Moreover, to determine the mechanical parameters of bread crust, the penetration test (McCarthy et al., 2005), the puncture crust test (Altamirano-Fortoul et al., 2012), the cutting test (Fik and Surówka, 2002) and the fracturability test (AltamiranoFortoul et al., 2015) are utilized.

In our previous studies, we analyzed the impact of plant additives such as carob fiber, red quinoa and black oat (Siastała et al., 2014, 2015, 2016) on the textural properties of wheat bread. Carob fiber, a valuable additive, is used in food production due to the content of two components i.e. polyphenols and dietary fiber. According to Haber et al. (2002), a $6 \%$ addition of carob fiber to rye bread reduces

(C) 2017 Institute of Agrophysics, Polish Academy of Sciences

*Corresponding author e-mail: monika.wojcik@up.lublin.pl 
the cholesterol level, especially the LDL. The second mentioned addition, quinoa, is rich in protein, minerals, fiber and vitamins. Quinoa is a good source of folic acid and vitamin $\mathrm{E}$, both of which have strong antioxidant properties (Bhargava et al., 2006; Comai et al., 2007; Iglesias-Puig et al., 2015). According to Stikic et al. (2012), a 10\% replacement of wheat flour with quinoa flour does not reduce the quality of bread (dough stability, loaf volume, weight, texture, taste and colour), and may be recommended for the bread making process. Black oat is a cultivar of brown husk which contains higher levels of amino acids and higher protein nutritional value as compared to yellow, grainy cultivars. In addition, the grains of the black oats contain enhanced levels of $\mathrm{Fe}$ and $\mathrm{Mn}$, and also contain more fiber and less starch than other cultivars (Ciołek et al., 2008; Gambuś, 2006).

A variation of plant additives in the wheat bread would result in different volume, water content and morphology of crumb. By creating a mixture of different components, we can produce a beneficial effect on the crumb texture properties, even when the single additive caused the reduction of loaf volume and the increase of crumb hardness, e.g., bread wheat supplemented with black oat (Siastała et al., 2016). Given the substantial need to examine the reciprocal influence of these additives on the bread quality and textural properties, and basing on previous studies, in our work, experimental baking was carried out with the use of these as mixtures of various degree. Thus, the aim of the present study was to investigate the effect of the mixture of plant components (MPC) on the physical properties of wheat bread. Emphasis was placed on understanding the effect of such on the mechanical properties of the crumb and crust of wheat bread.

\section{MATERIALS AND METHODS}

The white wheat flour was obtained from a local mill. The MPC included carob fiber made by Carob General Application, Valencia, Spain (Haber, 2002); milled grain red quinoa, purchased from the local market (manufactured by BIO PLANET S.A.) and milled black oat, coming from the local harvest of 2012. The red quinoa grain and black oat were ground into a whole meal flour (particles below $0.35 \mathrm{~mm}$ ), using a laboratory disc mill (type WŻ-2 Sadkiewicz Instruments, Bydgoszcz, Poland). Other ingredients used for the recipe were: dried instant yeast (Instaferm) originated from Lallemand Iberia, SA. and salt, which was purchased from the local market in Poland.

All chemical analyses of the wholegrain flours and carob fiber were conducted in three replicates. We assessed the moisture content (ISO 712:2009), protein content (ISO 20483:2006), ash content (ISO 2171:2007), fat content (ISO 11085:2008) and crude fiber content (AOAC 978.10, AACC 32-10 and AOCS Ba 6-84, using Fibertec 2010
(FOSS Analytical, Hilleroed, Denmark). In addition, with regard to the wheat flour, a falling number test was conducted (ISO 3093-1:2009) in order to assess wet gluten content (ISO 21415-1:2006).

The wheat flour we used had the following characteristics content: $12.7 \%$ of protein, $0.72 \%$ of ash, $31.2 \%$ of wet gluten, $1.27 \%$ of fat, and the falling number of $330 \mathrm{~s}$. The carob fiber was characterized by a protein content of $6.2 \pm 0.24 \%$, a total dietary fiber content of $24.3 \pm 0.98 \%$, and a fat content of $0.7 \pm .02 \%$. The red quinoa was defined by having a protein content of $13.8 \pm 0.55 \%$, a total dietary fiber content of $0.22 \%$, and a fat content of $5.9 \pm 0.22 \%$. The black oat showed a protein content of $14.4 \pm 0.57 \%$, total dietary fiber content $10.6 \pm 0.42 \%$, and a fat content of $4.7 \pm 0.20 \%$. All plant additives were characterized by similar ash content of $2.2 \%$ and moisture content of approx. $12 \%$. The MPC included carob fiber, milled grain red quinoa and black oat (1:2:2), and were added at percentages of $5,10,15,20,25 \%$ into the wheat flour. The control sample consisted of bread without the addition of the MPC. The testing of fermentation properties of the resulting flour mixtures was performed using fermentograph (type BZS model S Sadkiewicz Instruments, Bydgoszcz, Poland). The experimental baking test was done using a single-phase dough preparation method. For the preparation of the dough, fermentation and the baking of the resulting bread, we used laboratory machines, such as a mixer and a laboratory oven with a fermentative chamber (Sadkiewicz Instruments, PL).

The basic dough of the recipe of bread contained $600 \mathrm{~g}$ of flour, salt $(2 \%)$, yeast $(3 \%)$, and water. The supplementation with MPC was controlled via a farinograph (ISO 5530-1:2013). All ingredients were mixed in a spiral mixer type GM-2 for $4 \mathrm{~min}$ at low speed. After mixing, the dough was rested in the fermentative chamber at $30^{\circ} \mathrm{C}$ and $75 \% \mathrm{RH}$, for $1 \mathrm{~h}$ (with $1 \mathrm{~min}$ perforation after $30 \mathrm{~min}$ of resting). After the end of the fermentation, the dough was divided and it was moulded by hand, and then the dough samples were transferred to loaf tins (weight $0.3 \mathrm{~kg}$; dimension $11 \times 11 \mathrm{~cm}$ top; $7.5 \times 7.5 \mathrm{~cm}$ bottom; $8.5 \mathrm{~cm}$ deep) and were placed to proofing, which was performed in the time required for optimal dough development. When the fermentation was completed, the loaf tins were placed in the laboratory oven to be baked at $230^{\circ} \mathrm{C}$ for $30 \mathrm{~min}$. The loaves were then allowed to cool down at room temperature. The cooled bread samples were packed in polyethylene bags and stored at $20 \pm 1^{\circ} \mathrm{C}$, and $45-50 \% \mathrm{RH}$. After $24 \mathrm{~h}$ storage the weight of bread and bread loaf volume was assessed, using the millet seed displacement method (Jakubczyk and Haber, 1983). The crumb brightness index was also estimated after $24 \mathrm{~h}$ with a type MB whiteness meter (Sadkiewicz Instruments, Bydgoszcz, Poland).

For further investigation, samples were obtained by cutting a slice of bread to the thickness of $14 \mathrm{~mm}$. The external parts of bread were rejected, and the central parts of the samples were taken for the testing of mechanical 
properties, employing a tubular knife with a diameter of $22 \mathrm{~mm}$. The samples were subjected to twofold compression at $60 \%$ relative to height, at the rate of $20 \mathrm{~mm} \mathrm{~s}^{-1}$, using a ZWICK Z020/TN2S strength testing machine, with the mount head loading with mandrel diameter of $25 \mathrm{~mm}$. In this study, we used the head of the range of force-load to $100 \mathrm{~N}$. In such work, the resulting relative error did not exceed $0.5 \%$. On the basis of two-bite TPA (curves 1 and 2), and by way of the testXpert V 7.1 simulation software the following parameters were determined (Gámbaro et al., 2006): hardness (peak force 1), cohesiveness (area $2 /$ area 1), springiness (wide of base of area 2/ wide of base of area 1) and chewiness (hardness x springiness x cohesiveness). The measurements were done in eight replicates for each of the analyzed samples of bread after 24 and $48 \mathrm{~h}$ storage.

In order to assess the mechanical properties of the crust, the crusts of bread samples after 24 and $48 \mathrm{~h}$ of storage were cut off from the top part of the bread sample with a slicer next, samples of bread crust were cut away with a tubular knife. From these, the adhered crumb was carefully separated. The obtained samples were placed in a specially constructed attachment (Fig. 1) to the strength testing machine. In the hole of this attachment, a mandrel having a diameter of $6 \mathrm{~mm}$ was placed, and by way of an upper moveable plate, the measurement of mandrel displacement via loading was undertaken. The measurement continued until the sample's crust was punctured. On the basis of the aforementioned characteristics, crust failure force $(\mathrm{N})$ and crust failure work $(\mathrm{mJ})$ were specified.

Sensory evaluation of bread was made by a team of sixty seven evaluators (20-50 years old). The samples were obtained by cutting mechanically slices of bread measuring $14 \mathrm{~mm}$ in thickness. These were coded and served (randomly) for evaluation, in identical containers. The sensory test was conducted using a seven-point hedonic scale, where 1 - dislike very much, 2 - dislike moderately, 3 dislike slightly, 4 - neither like nor dislike, 5 - like slightly, 6 - like moderately and $7-$ like very much. The sensory attributes evaluated were taste, odor, crumb colour, texture and overall acceptability (Lazaridou et al., 2007).

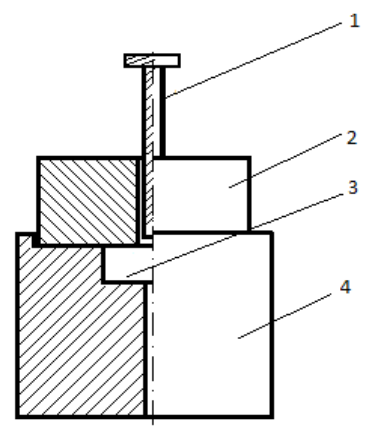

Fig. 1. Attachment to test the mechanical properties of bread crust: 1 - mandrel destructive, 2 - the upper cylindrical part, 3 - space to place the sample, 4 - the lower cylindrical part.
The results were statistically analyzed for significance level of $\alpha=0.05$, using Statistica 6.0 PL Statsoft. The statistical calculations included the analysis of variance (ANOVA) and when significant differences were detected, the mean values were compared using the Tukey's test.

\section{RESULTS AND DISCUSSION}

Table 1 presents the changes in the physical characteristics of dough and wheat bread containing the MPC. The increase of the addition of the MPC in wheat flour significantly increased the water absorption of the resulting flour mixtures. Higher water absorption while kneading is associated with fiber-rich doughs, because of the highly hygroscopic properties of dietary fiber. As reported by Miś et al. (2012), wheat dough with carob fiber has high water absorption and has enhanced rheological dough stability during mixing. From a technological point of view, higher water absorption is generally positive. This parameter also determines dough yield and bread yield. Bread enriched with the MPC was characterized by a slightly higher yield compared to the control bread. However the addition of the MPC to flour, in particular, at $25 \%$, resulted in smaller growth of dough in the fermentation (volume increase of approximately $238 \%$ with $25 \%$ of MPC), and, consequently, a lower final volume of bread was obtained.

Bread volume is considered one of the more important parameters in assessing the quality of bread (Kasprzak and Rzedzicki, 2010). According to previous studies, the addition of red quinoa, black oat (Siastała et al., 2015, 2016) and carob fiber at higher levels greater than 5\% brings about a decrease of bread volume. In our work, with the increase in the MPC content from 5 to $20 \%$, a linear increase of this parameter was observed $(\mathrm{R}=0.93)$. This can be explained in that the carob fiber as one component of mixture, strengthens the structure of gluten and enhances the bread's structure. Adding the MPC directly to the wheat flour gives satisfactory loss of baking at the level of $8 \%$. With the increase of the MPC addition, the density of bread crumb decreased slightly, but significantly.

Moreover, since the crumb brightness index determines the brightness of the flour's colour (the degree of brightening), in general, the presence of the MPC in bread darkened the colour of the crumb. This was reflected in lower values of crumb brightness index (from $36.7 \%$ for control sample, to 5.7 for $25 \%$ of the MPC).

In the analysis of the textural properties of bread crumb after $24 \mathrm{~h}$ of storage, it was found that increasing MPC addition had no influence on crumb hardness (which held a value at a similar level as the control sample). After $48 \mathrm{~h}$ storage, the hardness of crumb, however, increased, as a result of the bread staling. Still, significant differences were only detected between the control bread and 5\% MPC bread. Our previous studies revealed that supplementation with black oat flour decreases the bread crumb hardness the 
Table 1. Effect of different levels of MPC on the physical characteristics of dough and bread

\begin{tabular}{|c|c|c|c|c|c|c|c|}
\hline \multirow{2}{*}{$\begin{array}{l}\text { Physical } \\
\text { characteristics }\end{array}$} & \multirow{2}{*}{ Units } & \multicolumn{6}{|c|}{ Amount of MPC (\%) } \\
\hline & & 0 & 5 & 10 & 15 & 20 & 25 \\
\hline $\begin{array}{l}\text { Water absorption } \\
\text { flour }\end{array}$ & $\%$ & $55.6 \mathrm{a} \pm 0.4$ & $56 \mathrm{a} \pm 0.1$ & $57 \mathrm{~b} \pm 0.16$ & $58 \mathrm{c} \pm 0.11$ & $58.7 \mathrm{~d} \pm 0.15$ & $59 \mathrm{~d} \pm 0.1$ \\
\hline $\begin{array}{l}\text { Max growth of } \\
\text { dough volume }\end{array}$ & $\%$ & $257.4 \mathrm{a} \pm 3.12$ & $250.3 \mathrm{~b} \pm 5.20$ & $250.9 b \pm 5.5$ & $253.4 \mathrm{ab} \pm 3.3$ & $250.3 \mathrm{~b} \pm 3.2$ & $238.1 \mathrm{c} \pm 4.1$ \\
\hline Bread yield & $\%$ & $145.9 \mathrm{a} \pm 0.29$ & $146.2 \mathrm{a} \pm 0.29$ & $147.1 \mathrm{a} \pm 0.4$ & $148.5 \mathrm{~b} \pm 0.5$ & $148.4 \mathrm{~b} \pm 0.56$ & $149.1 \mathrm{~b} \pm 0.26$ \\
\hline Loss of baking & $\%$ & $8.0 \mathrm{a} \pm 0.24$ & $8.1 \mathrm{a} \pm 0.2$ & $8.1 \mathrm{a} \pm 0.23$ & $7.8 \mathrm{~b} \pm 0.38$ & $8.3 \mathrm{a} \pm 0.34$ & $7.9 \mathrm{a} \pm 0.31$ \\
\hline $\begin{array}{l}\text { Volume of } 100 \mathrm{~g} \\
\text { bread }\end{array}$ & $\mathrm{cm}^{3}$ & $248.3 \mathrm{a} \pm 6.1$ & $244.7 \mathrm{a} \pm 4.7$ & $263.6 b \pm 2.1$ & $271.2 b c \pm 6.2$ & $270.1 b c \pm 4.6$ & $278.2 \mathrm{c} \pm 4.8$ \\
\hline $\begin{array}{l}\text { Density of bread } \\
\text { crumb }\end{array}$ & $\mathrm{g} \mathrm{cm}^{-3}$ & $0.403 \mathrm{a} \pm 0.01$ & $0.410 \mathrm{a} \pm 0.01$ & $0.380 \mathrm{~b} \pm 0.01$ & $0.370 \mathrm{~b} \pm 0.02$ & $0.370 \mathrm{~b} \pm 0.01$ & $0.360 \mathrm{~b} \pm 0.01$ \\
\hline $\begin{array}{l}\text { Crumb } \\
\text { brightness index }\end{array}$ & $\%$ & $36.7 \mathrm{a} \pm 0.4$ & $16.1 \mathrm{c} \pm 0.4$ & $9.7 \mathrm{~d} \pm 0.3$ & $9.1 \mathrm{~d} \pm 0.1$ & $7.4 \mathrm{e} \pm 0.2$ & $5.7 \mathrm{e} \pm 0.1$ \\
\hline
\end{tabular}

Mean values designated with the same letters are not statistically different $(\alpha=0.05)$.

(Siastała et al., 2016). The opposite effect was obtained by enriching wheat flour with red quinoa flour and carob fiber (at levels higher than 2.5\%) (Siastała et al., 2014, 2015). Hence, varying the level of MPC resulted in different values of crumb hardness. As reported in numerous studies (Campbell et al., 2016; Różyło et al., 2014), during the staling of bread enriched with different plant additives, crumb hardness increases. In our study, the longer storage time did not change the hardness of the bread crumb - even with the addition of the MPC being higher than $10 \%$. According to Flander et al. (2007), adding oat to wheat bread might retard the staling rate of bread. Moreover, Wang et al. (2002) reported that texture profile analysis revealed softer crumbs when carob fiber is added to wheat flour.

We also saw that the cohesiveness of bread decreased after $48 \mathrm{~h}$ storage, yet, enriching bread with MPC had little effect on the changes in the value of this parameter. The highest cohesiveness was obtained for bread with $10 \%$ MPC ( 0.53$)$ and the lowest for bread with $25 \%$ MPC (0.33). Similar trends were previously observed following the addition of carob fiber and black oat flour. In these, while we observed a decrease of cohesiveness during the bread's storage, comparing MPC-enriched bread with the control sample, the value of this parameter did not change either under the influence of black oat flour or carob fiber enrichment (Siastała et al. 2014, 2016). Of note, Siastała et al. (2015) also found that there is a reduction of cohesiveness of bread crumb when the bread has been enriched with red quinoa flour.

In our work, MPC addition up to $10 \%$ had no significant influence on crumb springiness after $24 \mathrm{~h}$ of storage. Still, a higher share of the MPC brought about a slight decrease of this parameter. A similar tendency was observed for bread after $48 \mathrm{~h}$. However, significant differences were observed only between the control bread and that supplemented with MPC at $25 \%$.

We also saw that the chewiness of bread crumb did not change during storage and was characterized by values ranging from $3.1 \mathrm{~N}$ (control sample) to $1.1 \mathrm{~N}$ (bread with $25 \%$ MPC). However, increasing the proportion of MPC in wheat flour, especially at proportions higher than $10 \%$, resulted in decreased chewiness of crumb (average of more than $1 \mathrm{~N}$ ). Similar relations were obtained in our previous studies (Siastała et al., 2014, 2016), in which we did not observe any significant changes as regards post-storage crumb springiness and chewiness, in breads supplemented with carob fiber and black oat (Fig. 2).

By analyzing the force at which the destruction of bread crust is followed (Fig. 3A), we found that with the increase in the MPC content in wheat flour from 0 to $25 \%$, the crust failure force $\left(F_{c}\right)$ was reduced. For bread stored for $24 \mathrm{~h}$ $\mathrm{F}_{\mathrm{c}}$ values ranged from $16.1 \mathrm{~N}$ (for control sample) to $4 \mathrm{~N}$ (sample of bread with $25 \%$ MPC, after $48 \mathrm{~h}$ storage). According to Almeida et al. (2013), MPC supplementation of wheat flour affects crust mechanical properties by changing crust composition and influencing moisture migration in the crumb during storage (Almeida et al., 2013). Indeed, after $48 \mathrm{~h}$ of storage, the addition of MPC brought about a double reduction of $F_{c}$ (Fig. 3). This effect could be attributed to the method of bread storage, which after being cooled down, was packed in containers to prevent the loss of moisture. This might have induced higher water migration from the inner part of the bread crumb to the crust, thus, an increase of moisture content and the loss 

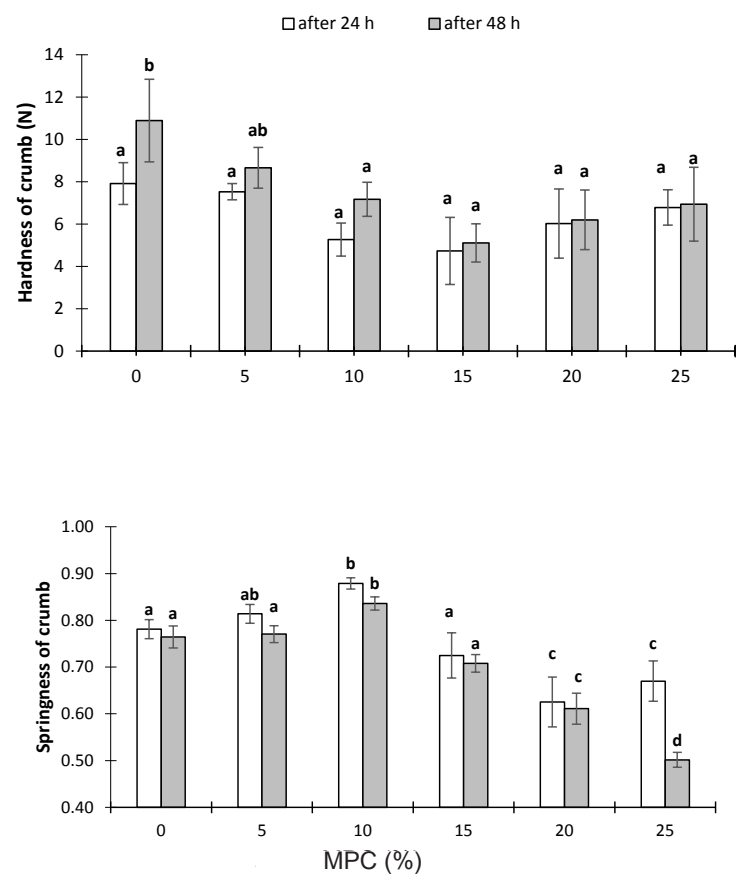

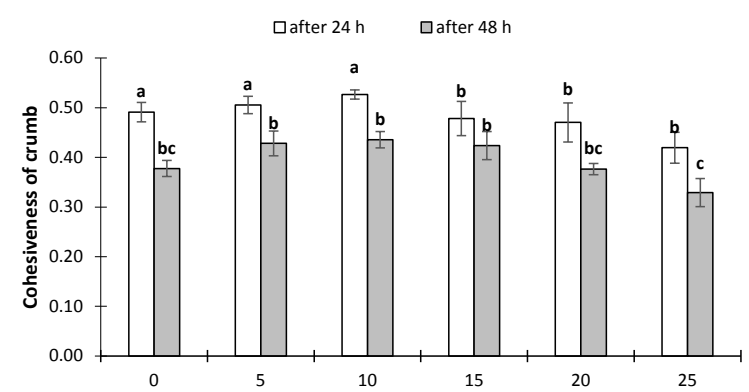

d

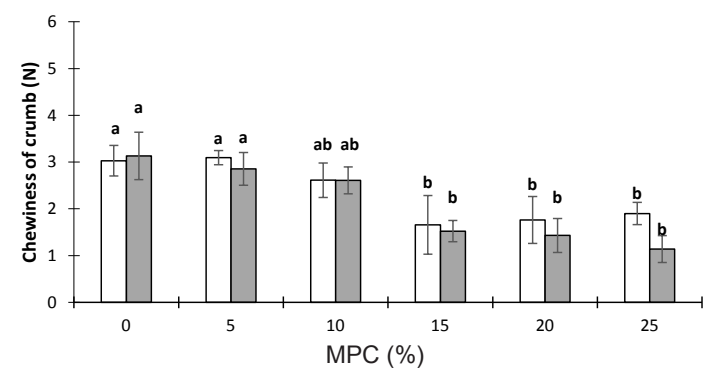

Fig. 2. Changes of textural properties of bread crumb as a result of MPC addition: $a-$ hardness, $b$ - cohesiveness, $c-$ springiness, $d-$ chewiness; mean values designated with the same letters are not statistically different $(\alpha=0.05)$.

a

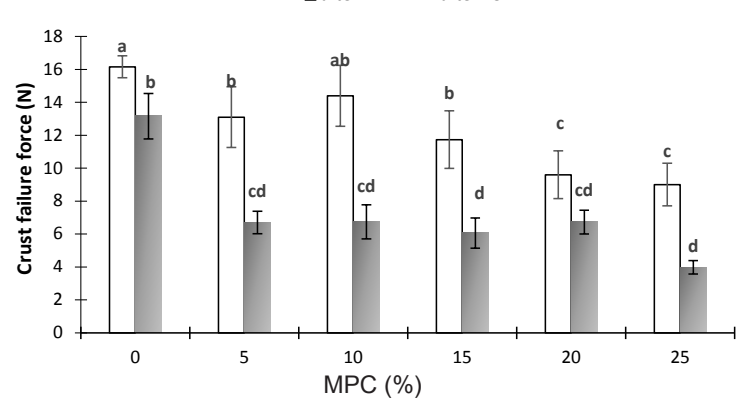

b

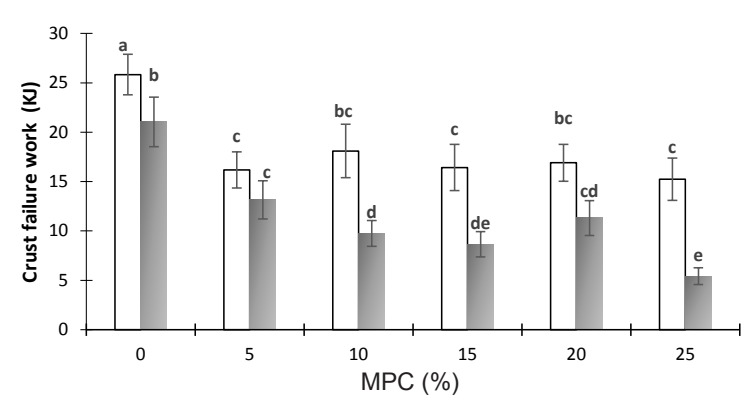

Fig. 3. Changes of crust failure force $(\mathrm{A})$ and crust failure work $(\mathrm{B})$ as a result of MPC addition, mean values designated with the same letters are not statistically different $(\alpha=0.05)$.

of crust strength. It can be said, then, that water migration into the outer layers of bread crumb contributes to the loss of crust hardness, and as a result, the crust will be softer (Cauvain and Young, 2008). Crust staling is mainly associated with the moisture migration from crumb to crust. This results in a soft and leathery texture (Stear, 1990; Bhatt and Nagaraju, 2009) and is associated with crust glass transition (Lin and Lineback, 1990).

The effect of the MPC addition on crust failure work $\left(\mathrm{L}_{\mathrm{c}}\right)$ is shown in Fig. 3B. The increase of the amount of the MPC induced a decrease in crust failure force. The lowest value of $\mathrm{L}_{\mathrm{c}}$ was observed for bread with MPC at $25 \%(5.4 \mathrm{~mJ})$, and the highest for a control sample $(21.1 \mathrm{~mJ})$. Therefore, the lower values in failure work indicate soft crust. In addition, $\mathrm{F}_{\mathrm{c}}$ was positively correlated with $\mathrm{L}_{\mathrm{c}}(\mathrm{R}=0.8)$.
The mean scores of the evaluated sensory attributes are presented in Table 2. The observed mean score of taste in the obtained bread ranged from 5.1 for bread with $25 \%$ MPC, to 5.9 for the control bread. Bread without additive and bread with $5 \%$ and $10 \%$ MPC were characterized as having the highest mean score in taste. As the share of the MPC in the bread recipe increased, lower notes for odor of bread were obtained (from 5.7 for bread without MPC, to 4.7 for loaves with $25 \% \mathrm{MPC}$ ). The addition of the MPC had the highest and most negative influence on bread colour. Loaves with MPC at higher than $10 \%$ were characterized by having a dull coloured crust, and, thus, held the lowest score for colour (3.6, 3.2, and 2.7 for bread with 15, 20 , and $25 \%$, respectively). Furthermore, MPC addition at rates higher than $10 \%$, negatively influenced bread texture. Generally, among the bread products, the control bread and 
Table 2. Results of bread quality assessment after $24 \mathrm{~h}$ of storage

\begin{tabular}{cccccc}
\hline Share of MPC (\%) & Taste & Odor & Colour & Texture & $\begin{array}{c}\text { Overall } \\
\text { acceptability }\end{array}$ \\
\hline 0 & $5.9 \mathrm{~b} \pm 0.21$ & $5.7 \mathrm{~d} \pm 0.25$ & $6.3 \mathrm{~d} \pm 0.35$ & $5.6 \mathrm{~d} \pm 0.28$ & $5.8 \mathrm{~d} \pm 0.31$ \\
5 & $5.7 \mathrm{~b} \pm 0.17$ & $5.5 \mathrm{~cd} \pm 0.18$ & $6.1 \mathrm{~cd} \pm 0.30$ & $5.3 \mathrm{~d} \pm 0.22$ & $5.5 \mathrm{~cd} \pm 0.27$ \\
10 & $5.6 \mathrm{~b} \pm 0.14$ & $5.2 \mathrm{bc} \pm 0.21$ & $5.8 \mathrm{c} \pm 0.24$ & $5.1 \mathrm{~cd} \pm 0.21$ & $5.4 \mathrm{c} \pm 0.29$ \\
15 & $5.3 \mathrm{ab} \pm 0.31$ & $4.9 \mathrm{ab} \pm 0.17$ & $3.6 \mathrm{~b} \pm 0.18$ & $4.5 \mathrm{~b} \pm 0.17$ & $4.6 \mathrm{~b} \pm 0.25$ \\
20 & $5.0 \mathrm{a} \pm 0.31$ & $4.8 \mathrm{a} \pm 0.19$ & $3.2 \mathrm{~b} \pm 012$ & $4.1 \mathrm{a} \pm 0.11$ & $4.2 \mathrm{a} \pm 0.16$ \\
25 & $5.1 \mathrm{a} \pm 0.18$ & $4.6 \mathrm{a} \pm 0.23$ & $2.7 \mathrm{a} \pm 0.15$ & $3.9 \mathrm{a} \pm 0.12$ & $4.0 \mathrm{a} \pm 0.14$ \\
\hline
\end{tabular}

Explanations as in Table 1.

MPC supplemented bread at levels up to $10 \%$ were highly acceptable, whereas loaves with higher MPC values held the lowest scores for quality parameters.

\section{CONCLUSIONS}

1. Wheat breads containing an additive of mixtures of plant components showed satisfactory physical properties. Mixture of plant components supplementation also significantly increased the water absorption of flour mixtures. The use of the mixture of plant components above 5\% resulted in an increase of bread volume and bread yield, and a decrease of crumb density.

2. The addition of the mixture of plant components had little influence on crumb hardness and cohesiveness. The highest cohesiveness was obtained for bread with $10 \%$ of additive, and the lowest for bread with mixture of plant components at $25 \%$. The values of chewiness of bread crumb, as well as springiness, did not change during storage.

3. Enrichment of wheat flour with mixture of plant components significantly reduced the crust failure force and crust failure work. Herein, $F_{c}$ value content ranged from $16.1 \mathrm{~N}$ (for a control sample), to $4 \mathrm{~N}$ (for a bread sample with $25 \%$ mixture of plant components - after $48 \mathrm{~h}$ storage). After $48 \mathrm{~h}$ of storage, mixture of plant components addition engendered an almost doubly reduced $F_{c}$ value.

4. The results of sensory evaluation showed that mixture of plant components addition up to $10 \%$ had little effect on bread quality. However, higher addition of this component especially negatively influenced the bread crust surface (generating a matt crust, with less attractive appearance).

5. Taking into account the physical properties of the resulting breads, and the sensory evaluation, mixture of plant components addition up to $10 \%$ is recommended.

Conflict of interest: The Authors do not declare conflict of interest.

\section{REFERENCES}

AOAC 978.10, 2005. Crude fibre. Official Methods of Analysis of AOAC INTERNATIONAL, AOAC INTERNATIONAL, Gaithersburg, MD, USA.

AACC 32-10, 2000. Crude Fibre in Flours, Feeds, and Feedstuffs. The American Association of Cereal Chemists, Cereal Laboratory Methods method, St. Paul, MN, USA.

AOCS Ba 6-84, 2009. Crude fibre. Official Methods and Recommended Practices of the American Oil Chemists' Society.

Almeida E.L., Chang Y.K., and Steel C.J., 2013. Dietary fiber sources in bread: Influence on technological quality. LWT - Food Sci. Technol., 50(2), 545-553.

Altamirano-Fortoul R., Hernández-Muñoz P., Hernando I., and Rosell C.M., 2015. Mechanical, microstructure and permeability properties of model bread crust: Effect of different food additives. J. Food Eng., 163, 25-31.

Altamirano-Fortoul R., Le-Bail A., Chevallier S., and Rosell C.M., 2012. Effect of the amount of steam during baking on bread crust features and water diffusion. J. Food Eng., 108, 128-134.

Besbes E., Jury V., Monteau J.-Y., and Le Bail A., 2014. Effect of baking conditions and storage with crust on the moisture profile, local textural properties and staling kinetics of pan bread. LWT- Food Sci. Technol., 58, 658-666.

Bhargava A., Sudhir S., and Deepak O., 2006. Chenopodium quinoa - an Indian perspective. Industrial Crops Products, 23, 73-87.

Bhatt C.M. and Nagaraju J., 2009. Studies on glass transition and starch re-crystallization in wheat bread during staling, using electrical impedance spectroscopy. Innovative Food Sci. Emerging Technol., 10(2), 241-245.

Campbell L., Euston S.R., and Ahmed M.A. 2016. Effect of addition of thermally modified cowpea protein on sensory acceptability and textural properties of wheat bread and sponge cake. Food Chemistry, 194, 1230-1237.

Ciołek A., Makarski E., and Makarski B., 2008. The content of some selected nutrients components in black and in yellow hull oats (in Polish). Food Sci. Technol. Quality., 3, 80-88.

Comai S., Bertazzo A., Bailoni L., Zancato M., Costa C., and Allegri G., 2007. The content of proteic and nonproteic (free and protein-bound) tryptophan in quinoa and cereal flours. Food Chemistry, 100, 1350-1355. 
Cauvain S.C. and Young L.S., 2008. Bakery food and manufacture and quality: Water control and effects. Wiley-Blackwell Press, Oxford, UK.

Fik M. and Surówka K., 2002. Effect of prebaking and frozen storage on the sensory quality and instrumental texture of bread. J. Sci. Food Agric., 82, 1268-1275.

Flander L., Salmenkallio-Marttila M., Suortti T., and Autio K., 2007. Optimization of ingredients and baking process for improved wholemeal oat bread quality. LWT, 40, 860-870.

Gambuś H., Gambuś F., and Pisulewska E., 2006. Oats wholemeal as a source of dietary elements in wheat bread (in Polish). Bull. IHAR, 239, 259-267.

Gámbaro A., Giménez A., Ares G., and Gilardi V., 2006. Influence of enzymes on the texture of brown pan bread. J. Texture Stud., 37, 300-314.

Haber B., 2002. Carob fiber benefis and applications. Cereal Food Word, 4, 41-47.

Iglesias-Puig E., Monedero V., and Haros M., 2015. Bread with whole quinoa flour and bifidobacterial phytases increases dietary mineral intake and bioavailability. Food Sci. and Technol., 60, 71-77.

ISO 5530-1:2013. Wheat flour - Physical characteristics of doughs - Part 1: Determination of water absorption and rheological properties using a farinograph.

ISO 712:2009. Cereals and cereal products - determination of moisture content - Reference method.

ISO 20483:2006. Cereals and Pulses - Determination of the Nitrogen Content and Calculation of the Crude Protein Content - Kjeldahl Method.

ISO 21415-1:2006. Wheat and Wheat Flour - Gluten Content Part 1: Determination of Wet Gluten by a Manual Method.

ISO 2171:2007. Cereals, pulses and by-products - determination of ash yield by incineration.

ISO 11085:2008. Cereals, cereals-based products and animal feeding stuffs - determination of crude fat and total fat content by the randall extraction method.

ISO 3093-1:2009. Wheat, Rye and Their Flours, Durum Wheat and Durum Wheat Semolina - Determination of the Falling Number According to Hagberg-Perten.

Jakubczyk T. and Haber T., 1983. Analysis of cereals and cereals products. Warsaw University of Life Sci. Press, Warsaw, Poland.

Kasprzak M. and Rzedzicki Z., 2010. Effect of pea seed coat admixture on physical properties and chemical composition of bread. Int. Agrophys., 24, 149-156.

Katina K., Heniniö R.-L., Autio K., and Poutanen K., 2006. Optimization of sourdough process for improved sensory profile and texture of wheat bread. LWT, 39, 1189-1202.

Lazaridou A., Duta D., Papageorgiou M., Belc C., and
Biliaderis C., 2007. Effects of hydrocolloids on dough rheology and bread quality parameters in gluten-free formulations. J. Food Eng., 79, 1033-1047.

Lin W. and Lineback D.R. 1990. Changes in carbohydrate fractions in enzyme supplemented bread and the potential relationship to staling. Starch, 42, 385-394.

McCarthy D.F., Gallagher E., Gormley T.R., Schober T.J., and Arendt E.K., 2005. Application of response surface methodology in the development of gluten-free bread. Cereal Chem., 82, 609-615.

Miś A., Grundas S., Dziki D., and Laskowski J, 2012. Use of farinograph measurements for predicting extensograph traits of bread dough enriched with carob fiber and oat wholemeal. J. Food Eng., 108(1), 1-12.

Rosell C.M. and Santos E., 2010. Impact of fibers on physical characteristics of fresh and staled bake off bread. J. Food Eng., 98, 273-281.

Różyło R., Dziki D., Gawlik-Dziki U., Cacak-Pietrzak G., Miś A., and Rudy S., 2015. Physical properties of gluten-free bread caused by water addition. Int. Agrophys., 29, 353-364.

Różyło R., Gawlik-Dziki U., Dziki D., Jakubczyk A., Karaś M., and Różyło K., 2014. Wheat bread with pumpkin (Cucurbita maxima L.) pulp as a functional food product. Food Technol. Biotechnol., 52(4) 430-438.

Siastała M., Dziki D., and Różyło R., 2014. The influence of carob pod fiber on textural properties of wheat bread crumb (in Polish). Problem Issues, 578, 111-119.

Siastała M., Dziki D., and Różyło R., 2015. Changes of physical properties of wheat dough and bread as a result of red quinoa flour addition (in Polish). Acta Agrophysica, 22, 291-300.

Siastała M., Dziki D., Różyło R., Biernacka B., Lysiak G., and Jawad al Aridhee, 2016. Changes of dough and wheat bread physical properties as a result of black oat flour addition (in Polish). Proc. V Symp. Food Engineering, June 21-23, Warsaw, Poland.

Stear A.C., 1990. Moisture movements during the cooling and maturation of bread. Handbook of bread making technology, barking, England: Elsevier Sci., 641-649.

Stikic R., Glamoclija D., Demin M, Vucelic-Radovic B., Jovanovic Z., Milojkovic-Opsenica D., Jacobsen S.E. and Milovanovic M., 2012. Agronomical and nutritional evaluation of quinoa seeds (Chenopodium quinoa Willd.) as an ingredient in bread formulations. J. Cereal Sci., 55, 132-138.

Škrbić B. and Filipčev B., 2008. Nutritional and sensory evaluation of wheat breads supplemented with oleic-rich sunflower seed. Food Chem., 108, 119-129.

Wang J., Rosell C.M., and Benedito de Barber C., 2002. Effect of the addition of different fibers on wheat dough performance and bread quality. Food Chem., 79, 221-226. 